\title{
How competency-based training locks the working class out of powerful knowledge: a modified Bernsteinian analysis
}

LEESA WHEELAHAN*

Griffith University, Australia ${ }^{1}$

\begin{abstract}
This paper argues that competency-based training in vocational education and training in Australia is one mechanism through which the working class is denied access to powerful knowledge represented by the academic disciplines. The paper presents a modified Bernsteinian analysis to argue that VET students need access to disciplinary knowledge using Bernstein's argument that abstract, conceptual knowledge is the means societies use to think 'the unthinkable' and 'the not-yet-thought'. I supplement Bernstein's social argument for democratic access to the disciplines, with an epistemic argument that draws on the philosophy of critical realism.
\end{abstract}

Keywords: competency-based training; academic disciplines; sacred and profane knowledge; vertical and horizontal discourse.

\section{Introduction}

This paper uses a modified Bernsteinian analysis to explore the way in which competency-based training in vocational education and training (VET) in Australia excludes the working class and other disadvantaged social groups from access to powerful knowledge, because it denies students access to the structuring principles of disciplinary knowledge. First, I outline the distinction that Bernstein makes between sacred and profane or esoteric and mundane knowledge, and the role each plays in society. This includes discussion of Bernstein's analysis of the structures of esoteric and mundane knowledge as vertical and horizontal discourses, and the way in which each type of knowledge is acquired. This is the basis for Bernstein's social argument for democratic access to the disciplines. Bernstein's main focus was on the social relations of knowledge, and not the epistemic relations. However, access to disciplinary knowledge is important for epistemic reasons as well as social reasons, and the paper draws on critical realism to establish this argument. Bernsteinian theory and critical realism constitute complementary approaches that together provide insights into the structures of knowledge, the content of knowledge, and the relationship between knowers and knowledge, which includes exploration of the social conditions under which knowledge is produced, and the extent to which these processes are mediated by power. The second section explains the emergence of competency-based training in Australia, and situates these reforms to VET within broader processes of policy reform by Anglophone neo-liberal governments, which sought to structure VET as training for industry. Bernsteinian theory is used to analyse the way in which the language of progressivism was transformed through its incorporation into the 'new vocationalism', and resulted in the 'controlled vocationalism' of current VET policy in England and in Australia, in ways that reinforce the power of employers (Bates, Bloomer, Hodkinson and Yeomans 1998; Jones and Moore 1995). The final section analyses VET policy and

\footnotetext{
1 *School of Vocational, Technology and Arts Education, Mt Gravatt campus, Griffith University, Brisbane, Queensland, 4111, Australia Email: 1.wheelahan@griffith.edu.au
} 
the structure of VET qualifications in Australia to demonstrate that while these qualifications may provide access to procedural knowledge or to products of disciplinary knowledge, that students do not gain access to the 'style of reasoning' within disciplinary structures of knowledge, which reduces the control students as workers have over knowledge in the work-place.

\section{Esoteric and mundane knowledge}

Moore and Muller (2002: 635) refer to Bernstein's approach as a "form of sociological realism in the Durkheimian mode”. Bernstein's (2000: 29) theory of knowledge is indebted to Durkheim in arguing that all societies distinguish between sacred or esoteric knowledge on the one hand, and profane or mundane knowledge on the other. Esoteric knowledge is theoretical and conceptual knowledge, while mundane knowledge is "knowledge of the other...knowledge of how it is (the knowledge of the possible)" (Bernstein 2000: 157). Durkheim and Bernstein imply that the distinction between esoteric and mundane knowledge is universal, while the content of each is culturally and historically specific.

Esoteric knowledge is sacred knowledge because historically religion was the paradigmatic form of theoretical and abstract knowledge, and mundane knowledge was profane knowledge because its concerns were the concerns of the profane, everyday world. Religions are in essence the collective representations of societies and reflect societies back to themselves. They express the general social relations of particular societies, and this is why religions differ between societies and epochs (Durkheim 1967: 29-30). Religion was paradigmatic for theoretical, abstract knowledge, which was later expressed as specialised forms of knowledge most associated with academic disciplines, because of the way in which religion negotiated the boundaries between the material and immaterial worlds, but also because religion, philosophy and science share the same concerns: "they are nature, man, society” (Durkheim 1967: 476).

The distinction between esoteric and mundane knowledge is the means through which society navigates between the concerns of everyday life (the mundane) and a 'transcendental' realm (Bernstein 2000: 29). Young (2003: 102-103) explains that esoteric knowledge for Durkheim consists of 'collective representations' of a society that allow it "to 'make connections' between objects and events that are not obviously related", and "to 'project beyond the present' to a future or alternative world." Collective representations are therefore the means societies use to transcend the limits of individual experience to see beyond appearances to the real nature of relations in the (natural and social) world. All societies need to connect the material and immaterial, the known and the unknown, the thinkable and the unthinkable, the here and the not here, the specific and the general, and the past, present and future. This capacity is a precondition for the existence of society.

\section{Vertical and horizontal discourse}

Bernstein elaborated Durkheim's distinction between esoteric and mundane knowledge through his exploration of the structures of knowledge in each case, and the social relations they are based on. He says that esoteric knowledge - or conceptual, abstract knowledge - is a form of vertical discourse, whereas mundane or everyday knowledge is a form of horizontal discourse, with different social relations underpinning each. 
Mundane knowledge is tied to specific contexts and events, so that the meaning of mundane knowledge is only understandable within that specific context and the material base it rests upon (Bernstein 2000: 30). Because meaning is context specific, meaning is consumed by that context and can't easily be applied elsewhere. This is why it is difficult for mundane knowledge to be a driver of change beyond the context in which it is enacted. The structure of mundane knowledge or horizontal discourse is segmented by the specific context in which it is realised (for example, the work-place, home or local sporting club). This gives rise to segmental knowledges, which are not necessarily transferable to other contexts except where features of the context and social relations are similar. Bernstein (2000: 157) says that horizontal discourse is "likely to be oral, local, context dependent and specific, tacit, multi-layered, and contradictory across but not within contexts." The principle through which knowledge is selected and applied is relevance to the local context, and the local context is usually the site in which learning that knowledge (and how to apply it) takes place. This means that meanings, knowledge and competences acquired in one context (or segment) do not necessarily have meaning or relevance in another (Bernstein 2000: 159).

In contrast, Bernstein (2000: 30) argues that much esoteric knowledge is potentially powerful knowledge because it constitutes the site of the 'unthinkable' and the 'yet-to-be-thought'. Esoteric knowledge has the potential to challenge the social distribution of power, because of its (not always realised) capacity to transform knowledge and how that knowledge is used. Such knowledge is indirectly related to a material base, and this means that there is a potential for a gap to arise between that knowledge and its material base, which Bernstein (2000: 30) refers to as the "potential discursive gap”. Bernstein (2000: 30) argues that this gap can "become (not always) a site for alternative possibilities, for alternative realisations between the material and immaterial" and can "change the relations between the material and immaterial." This is the site of the 'unthinkable', the 'impossible' and the 'not-yet-thought', and this is why esoteric knowledge has power and status, and why access to it is always regulated through a division of labour, and through distributive rules that provide access to some, but not others (Bernstein 2000: 31).

Esoteric or conceptual knowledge is structured as a vertical discourse, because, unlike horizontal discourse, knowledge is not segmented by, and integrated through, the specific context in which it is realised. Rather, Bernstein (2000: 160) explains that vertical discourse consists of "specialised symbolic structures of explicit knowledge" in which the integration of knowledge occurs through the integration of meanings and not through relevance to specific contexts. Bernstein (2000: 160) says that "The procedures of Vertical discourse are then linked, not by contexts, horizontally, but the procedures are linked to other procedures hierarchically." Vertical discourses take one of two main forms. The first form of vertical discourse "takes the form of a coherent, explicit, and systematically principled structure, [and is] hierarchically organised, as in the sciences...” (Bernstein 2000: 157). Physics or other natural sciences are examples of vertical discourses with hierarchical knowledge structures. The other "takes the form of specialised languages with specialised modes of interrogation and specialised criteria for the production and circulation of texts, as in the social sciences and humanities” (Bernstein 2000: 157). Unlike the acquisition of horizontal discourse (which is tied to specific contexts and largely only meaningful within that context), the process of acquiring vertical discourse is through induction into that strongly classified and insulated body of knowledge. The acquisition of vertical discourse requires the development of the capacity to integrate meanings so that these meanings "are not consumed at the point of its contextual delivery" (Bernstein 2000: 160). Students need to acquire the capacity to integrate knowledge (and underpinning principles) through systems of meaning bounded by the discipline in ways that transcend the particular application of specific 'products' of disciplinary knowledge in specific contexts. Rather than learning the isolated and unconnected contents of disciplinary knowledge, students need to learn the systems of meaning. 


\section{A realist ontology}

Bernstein's (2000: xx) analysis of the nature of esoteric and mundane knowledge, and the structure of the discourse that underpins each, demonstrates the reasons why access to abstract, disciplinary knowledge is important, and is the basis of his argument against the lack of democratic access to such knowledge. However, Bernstein was primarily concerned with the social relations of knowledge, and his argument does not, on its own, constitute an argument based on the epistemic relations of knowledge (Moore and Maton 2001). Beck and Young (2005: 185) explain that Bernstein was less concerned with the internal content of disciplinary structures of knowledge, and that he was agnostic about their epistemological standing. Moore (2004: 142) argues that Bernstein's insistence that theories generate languages of description about their objects of study "...in such a way that the theory is independently tested against reality and open to modification in light of that testing" means that Bernstein was insisting on "an external ontological imperative...” I think Moore is right, but this is an area where Bernstein's argument was implicit and underdeveloped, because his focus was on the structures of knowledge, which he considered to be an independent question to the question concerning the content of knowledge.

Moore (2004: 148) explains that the sociology of education must be concerned about the production of knowledge, as well as its more traditional concerns about the way in which different fields of knowledge are classified within the curriculum. He compares and contrasts constructionist and realist approaches to the production of knowledge. Constructionism insists on the relativism of all knowledge; knowledge is defined through (and reduced to) the perspective of the knower, through denying the existence of an independent objective reality. Realist approaches concede that knowledge is a social product and that it is fallible as a consequence, but that an objective reality exists, and that the purpose of knowledge is to understand that objective reality, even if our knowledge is always impartial, socially mediated, and marked by the social conditions under which it was produced, which includes power and privilege. My goal here is to argue for the latter, without engaging in debate with the former. ${ }^{1}$

Critical realists argue that we need to go beyond underlying appearances or events to understand the connections that produce the reality that we experience (Sayer 2000). This is because the world is complex and stratified. The outcomes we experience are always the product of co-determination of different causal mechanisms that interact in open systems (Bhaskar 1998). For example, Collier (1998: 263) explains everything is governed by the law of physics; some, but not all things are governed by the laws of biology; and more recently, some but not all things are governed by the law of capitalist economics. The causal mechanisms operating within these different strata (and others not identified here) interact to make factory production possible. Critical realism is a relational philosophy because it examines the interplay between different objects and strata, arguing "that the world is characterised by emergence, that is situations in which the conjunction of two or more features or aspects gives rise to new phenomena, which have properties which are irreducible to those of their constituents, even though the latter are necessary for their existence" (Sayer 2000: 12). For example, even though societies comprise lots of individuals and could not exist without them, adding up all the individuals who live in a society does not express the totality of that society. Society is more than the sum of its parts, and the nature of society reacts back to affect the individuals and other factors (such as material and social resources) that make society possible. We have to go beyond our experiences and beyond the events that take place in the world to understand the nature of the generative mechanisms that cause these events and experiences. An example of a causal mechanism in the social world is social class, 
while gravity is an example in the natural world. However, even though critical realists argue that the natural and social worlds are characterised by stratification, co-determination and emergence, this doesn't mean that we can use the same methods to study each. This is because the objects we are studying do not have universal properties, and this means that it is not possible to use universal methods to explore those objects (Archer 1995).

Critical realists argue that knowledge arises from our practice in the world (Bhaskar 1998; Sayer 2000). As our practice leads to better knowledge of the world, changes ensue in the classification and structures of knowledge. Changes in the structure of the disciplines occur as a consequence of the interplay between social relations, our practice, and insights from already existing knowledge in other disciplines. This is because the academic disciplines are themselves complex realities. They are partly constituted by arbitrary social relations because they are social products, but they are also partly constituted by the objects they seek to study, and this means that the division between the disciplines is not wholly arbitrary (Collier 1997, 1998). Some disciplines, like physics or chemistry, provide insights into aspects of the world, by identifying causal mechanisms in isolation of their operation in open systems. Other disciplines, like all the human sciences, focus on the emergent outcome of many causal mechanisms operating at different levels (Collier 1997, 1998).

Access to disciplinary knowledge is important for epistemic reasons because it provides students with access to the 'collective representations' about the causal mechanisms that the discipline studies, mechanisms that are not always accessible through direct experience (or problem-based learning). The disciplines provide students with access to the relational connections within a field of study and between fields, and students need access to the disciplinary "style of reasoning" (Muller 2000: 88) to move beyond a focus on isolated examples of content. Specific content is the product of disciplinary knowledge; it is not knowledge about the generative mechanisms (and the relations between them) that the discipline studies. If the world is characterised by ontological depth, stratification, emergence and co-determination then students need to understand these processes, and not have their understanding restricted to the level of events or experiences. These are the epistemic reasons why access to the disciplines is important. However, interdisciplinary research is necessary to understand concrete particulars (the things that exist or happen in the world), because concrete particulars are always a consequence of co-determination of many different mechanisms (as in the earlier example of factory production). Such interdisciplinary work takes place however, through explicitly negotiating disciplinary boundaries rather than their negation.

\section{The broad context for the introduction of CBT in VET in Australia}

The introduction of CBT in Australia was as a consequence of similar neo-liberal reforms as those in the United Kingdom (particularly England), which sought to recast education, and particularly VET, as an instrument of micro-economic reform. There are many parallels as well as differences between the two systems, as each nation sought to develop specific reforms in response to imperatives generated by the social, cultural, economic, and technological changes associated with globalisation (Priestley 2002).

Competency-based training was introduced in the 1980s and 1990s in Australia as part of broader industry restructuring to increase Australia's competitiveness in an increasingly globalised economy (Goozee 2001: 62). CBT was introduced in VET in Australia by a Labor government, as part of broader reforms to all sectors of education through seeking to subordinate education to economic needs, and to align 'skill' development with the 'needs' of the economy. There was bipartisan support for the reconstruction of VET according to the 
principles of human capital theory. Labor and conservative governments have, since that time, redefined VET as training for industry, according to industry-defined outcomes, as part of a broader reform process that sought the development of a competitive VET 'market' to make VET more 'responsive' to the needs of industry (Goozee 2001: 90).

Bates et al., (1998: 113), in discussing the introduction of CBT in England, explain that "whereas the old vocationalism was about preparing trainees for specific jobs, the new vocationalism aimed at preparation for work in general.” I have applied their analysis to Australia, because the resonances are so strong. They explain that despite the historical antipathy between vocationalism and progressivism, that the 'new vocationalism' of the 1980s was infused with the language of progressivism.

The language of progressivism was strongly associated with the introduction of CBT in Australia. Indeed, the Australian Council of Trade Unions was among the most enthusiastic supporters of the introduction of CBT and helped to develop and implement the new VET system and new VET qualifications through their participation in corporatist mechanisms established by the then Labor government (Goozee 2001). The introduction of CBT would, it was argued, increase participation in education and training, provide unparalleled access to education and training for people from disadvantaged backgrounds, recognise and certify the skills of existing workers, create access to on and off the job training for workers, help to overcome occupational segregation based on gender divisions or outdated craft divisions, increase private and public investment in training, and improve the quality and flexibility of the training system (Goozee 2001: 63 - 64).

Vocationalism drew from progressivism a rejection of "the centrality of disciplinary knowledge and school subjects in definitions of the curriculum" (Bates et al. 1998: 111). This is because progressivism (in the tradition of Rousseau, Blake and the Romantic movement) (Bates et al. 1998: 110) was concerned primarily with the development of the intrinsic capacities of the child/student, and so the task of the teacher was not to instil disciplinary knowledge, but to "expose students to situations in which they could construct their knowledge of the world” (Bates et al. 1998: 111). Bloomer (1998: 168) explains that the reworked progressivism drew from the liberal market ideologies that were driving the new vocationalism the language of "consumer rights, freedom and individuality” which were seen as "inherently and morally good."

In Australia as in England, the 'new vocationalism' of the 1970s and early 1980s was transformed into 'controlled vocationalism' that granted increased control to the state and to employers in specifying the outcomes of VET (Bates et al. 1998: 114). An important difference between Australia and England is that the Learning and Skills Sector in England offers a range of general, second chance and higher education programmes as well as VET qualifications, which are based on National Vocational Qualifications (NVQs). However, under the new UK funding arrangements these possibilities for non-competence based programmes are fast disappearing as in the case of the workers educational associations. There are fewer options in Australia. In VET in Australia, publicly funded provision leading to qualifications must be based on training packages, which are the equivalent of NVQs. Some further education programs still exist, but they are marginal and their future is threatened unless they can demonstrate a labour market outcome. In most cases, the only way that VET providers can escape these restrictions and offer a qualification normally accredited in another sector is through full fee, and not publicly funded, programs (Wheelahan and Moodie 2005).

Jones and Moore (1995: 81) explain that educational policy must be located within the political context in which it arises, and this helps us to understand the way in which the progressivism of the new vocationalism was transformed into controlled vocationalism. They explain that the "political and policy context act 
selectively upon the realisation of the various possibilities suggested by different approaches to competence... Whether it is the controlling or emancipatory possibilities that come to be realised will be settled not by theoretical or definitional debates but within real world, institutional contexts..." (Jones and Moore 1995: 81-82). The real world, institutional policy context acts by selectively borrowing from other discourses and constructs "an approach appropriate to the particular objectives of the agency assembling it" (Jones and Moore 1995: 83).

In drawing from Bernstein, Jones and Moore explain that the broader policy context constitutes the regulative discourse through providing the principle of recontextualisation that is used to construct the explicit, instructional discourse. The policy discourse of competence borrowed from theories "originally developed within disciplines in the academic sphere [which] are taken out of that context and reassembled, in an appropriate form, within the institutional space of the agency concerned" (Jones and Moore 1995: 83). They explain that educational policy development is characterised by two processes: the first is the process of recontextualisation, in which ideas and concepts are selectively appropriated into an instructional discourse, but the realisation of the instructional discourse is always embedded in the regulative discourse, and the parameters of regulative discourse are shaped by the particular model of social order (in this case, neoliberalism) pursued by government policy. The principle of recontextualisation points backwards, to the different origins of the instructional discourse. It tells us where the discourse has come from. This was the way in which progressivism was reworked and transformed through the new vocationalism. The second process Jones and Moore (1995: 83-84) refer to is the process of incorporation, which refers to the way "in which the discourse incorporates those aspects of social life that are the primary concern of the agency." This tells us the direction in which the discourse is travelling, or where it is going. The introduction of competency-based training in England (and in Australia) 'incorporates ‘the world of work' according to its own particular principles and rules” (Jones and Moore 1995: 84).

The world of work imagined in policy (at least in Anglophone, liberal market economies) is the 'natural' free market populated by entrepreneurial, flexible workers who take responsibility for their firm's outcomes, but without the hierarchical (and expensive) management structures characteristic of Fordism (Bates et al. 1998: 116). Bates et al. (1998: 117) explain that "All these arguments hinge upon the notion of improving an organisation's competitive edge and imply a unitary model of employer-employee relations." The outcomes of work are not problematised and policy takes for granted that the purpose of education is to "revolve around the cultivation of appropriate skills and attitudes for employment" (Bates et al. 1998: 115). The outcomes of education (particularly VET in England and in Australia) were similarly redefined as unproblematic 'descriptions' of the skills needed by employers.

This process is being driven further in Australia, and all VET qualifications will be revised so that they incorporate the newly endorsed 'employability skills'. These skills must be "front and centre" of VET qualifications as they are redeveloped (Department of Education Science and Training [DEST] 2005: 160). These employability skills will replace the existing broader 'key competencies' because the latter "were too generic in their approach and no longer reflected the needs of contemporary workplaces" (Cleary, Flynn and Thomasson 2006: 10). The new employability skills are even more tightly tied to work than were the previous key competencies, and are defined as:

- "Communication that contributes to productive and harmonious relations between employees and customers"

- "Teamwork that contributes to productive working relationships and outcomes" 
- "Problem solving that contributes to productive outcomes"

- "Initiative and enterprise that contributes to innovative outcomes"

- "Planning and organising that contribute to long-term and short-term strategic planning"

- "Self-management that contributes to employee satisfaction and growth"

- "Learning that contributes to ongoing improvement and expansion in employee and company operations and outcomes"

- "Technology that contributes to effective execution of tasks" (DEST 2005: 181-184)

Williams (2005: 45) explains that the discourse around employability skills is a normalising exercise, in which the desired attributes of 'learner-workers' are defined according to the dominant values, beliefs and expectations of the dominant culture. The definition of employability skills here shows that this is indeed the case, if we define dominant culture as the near hegemonic dominance of employer interests in government policy and in the VET system.

\section{VET qualifications in Australia}

As the previous section explains, the only qualifications that are accredited in the VET sector are training packages, which are the equivalent of the English NVQs, or programs that consist of industry-specified units of competency if an argument can be made that there is no suitable training package. VET qualifications prepare students for occupations across all industries at different skill levels, and are not limited to the traditional trades.

The introduction of training packages caused fierce debate within Australia, so much so, that Schofield and McDonald (2004) called for a 'new settlement' to underpin training packages in their report on the high level review of training packages in 2004. Training packages have been criticised for many reasons, but particularly by teachers because of concerns that they downplay the importance of underpinning knowledge (Smith and Keating 2003: 169). This section provides a theoretical explanation for teachers' concerns.

Training packages are developed for broad industry areas (such as community services), and each training package comprises a number of qualifications at different levels. Qualifications are made up of industryspecified units of competency that are specified in the training package, and many units of competency are shared between qualifications. Each unit of competency consists of a number of elements of competency, employability skills, performance criteria, a range statement that describes the likely contexts in which the competency will be deployed, and evidence guides to guide assessment. The Training Package Development Handbook (DEST 2005: 105) defines competency as follows:

"Competency comprises the specification of knowledge and skill and the application of that knowledge and skill to the standard of performance required in the workplace."

Units of competency must be related to realistic work-place practices. The Handbook specifies the way in which knowledge should be handled in units of competency. The latest edition of the Handbook (DEST 2005: 109-10) stipulates that:

"In recognition of the importance of knowledge in skills application and skills transfer, units of competency must detail the underpinning knowledge required for competent performance. 
The application of knowledge is often the key to the transfer of competency to new situations. Underpinning knowledge will often need to be assessed in order to ensure that the person understands the 'why' as well as the 'how'. Clear articulation of the required underpinning knowledge will support training and assessment of the unit of competency.

However, while knowledge must be expressed, units of competency, their elements or performance criteria should not be entirely knowledge based unless a clear and assessable workplace outcome is described. Knowledge in units of competency:

- should be in context;

- should only be included if it refers to knowledge actually applied at work..."

Later on, the Handbook (DEST 2005: 134) says that:

"Competent performance must result in a realistic expression of knowledge through problem solving, prediction of outcomes, cause and effect, or similar dynamic process specific to the unit."

This is a very fragmented, atomistic and instrumental view of knowledge. It is premised on positivist views of knowledge, in which knowledge is reducible to statements about correlation and prediction. Knowledge is not and cannot be always about prediction of outcomes, unless we are limiting our statements to observation of cause and effect in closed systems (Bhaskar 1998), and this certainly does not describe the world of work or any aspect of the social world. Knowledge is about understanding. Moreover, the Handbook posits an atomistic view of knowledge, which carves up the knowledge needed in a particular area, and then renders it all equal. For example, the unit of competency 'Advocate for clients', which is part of the Community Services Training Package (Community Services and Health Industry Skills Council 2005: 81), has three elements of competency:

1. Assist clients to identify their rights and represent their own needs

2. Advocate on behalf of clients on request

3. Advocate for clients

There are nine performance criteria (although one of these has three components). The 'essential knowledge' included in the evidence guide consists of the following:

- "Organisations and services relevant to the nature of client service

- Referral options and resources available to community

- Organisational policies and procedures

- Relevant legal and other rights/limitations

- Social justice principles

- Differences between negotiation, advocacy, mediation and conciliation” (p. 83)

Social justice principles and the difference between negotiation, advocacy, mediation and conciliation are not differentiated from the other components of necessary knowledge (or from each other even though social justice is at a different level of theorisation than are the applied concepts of negotiation, advocacy, mediation and conciliation), yet some of these elements are clearly procedural and of less importance than the underpinning broad sociological knowledge that is needed to successfully understand the context in which advocacy takes place. Not all knowledge is of equal importance or of the same type. 
Moreover, this approach assumes conceptual knowledge can be unproblematically defined. Social justice principles are called for in the above example, yet the concept of social justice is related to the nature of the human actor. What kind of human actor is assumed? The designation of 'clients' suggests that a consumer relation is posited. This demonstrates the folly in assuming that it is possible and desirable to identify specific knowledge associated with work that is separated from the system of concepts that give it meaning, and then unproblematically teach and assess it. The capacity to use particular knowledge at work is an emergent capacity that emerges from broader knowledge, skills and attributes. In this case, some understanding about different ways in which philosophy or sociology define agents and their relationship to society seems to be essential knowledge that community workers use to 'know with' and interpret particular situations. Prior to the introduction of the training package, the students enrolled in a community development program that I used to teach in undertook subjects such as human rights and advocacy, sociology, and politics, and students were required to explore the contests over different understandings of agency and the implications these had for practice. In other words, the program I used to teach in stood at the interface between disciplinary knowledge and the field of practice (Bernstein 2000: 52), and while the field of practice provided the rationale for selection and translation of knowledge in the curriculum, it was still based on explicit engagement with disciplinary knowledge.

Bernstein's insights allow us to see that CBT fundamentally transforms the nature of knowledge by delocating it from the vertical discourse in which it is classified and relocating ${ }^{2}$ it closer (if not completely) towards horizontal discourse. This changes the nature of knowledge, and the processes through which it is acquired. Rather than integration of meanings we have integration within a context. Consequently, students are provided with access to specific content, and not the systems of meaning in disciplinary knowledge. However, the content of a discipline is the product of the discipline (and each discipline has lots of 'products'); it is not the generative principles used within the discipline to create new knowledge and nor does a focus on content provide the criteria needed to select the knowledge needed in new contexts. Content is disaggregated so that it consists of isolated 'bits' of knowledge. A focus on specific content for a specific context means that the meaning of that content is exhausted by the context. Unless students have access to the generative principles of disciplinary knowledge, they are not able to transcend the particular context. Students need to know how these complex bodies of knowledge fit together if they are to decide what knowledge is relevant for a particular purpose, and if they are to have the capacity to transcend the present to imagine the future. Knowledge is not under their control. This simultaneously denies them epistemic access to the structures of knowledge relevant in their field and social access to the 'unthinkable'.

Critical realism extends these Bernsteinian insights, because a focus on the specific content of disciplines denies students access to the 'collective representations' that provide access into the stratified and emergent nature of the real. This 'absence' arises from the broader ontology and epistemology of CBT, which is a form of empirical realism (based on atomism in ontology and epistemology). By focussing on the knowledge and skills that people need to 'do' their job, and by insisting that assessment be directly aligned with these outcomes, CBT collapses the domain of the real (of generative mechanisms) and the domain of the actual (where events take place) into the domain of the empirical (that which is observable). It does so, because CBT assumes that outcomes can be achieved by directly teaching to the outcomes, and in doing so ignores the complexity that is needed to create capacity, and this goes beyond the level of experience in the contextual and situated. Teaching and learning must engage the real and the actual and not just the empirical, because this is the only way to generate a varying and contextually sensitive performance in a variety of contexts. In contrast, CBT breaks skills down into discrete components, which can be packaged as competencies, then 
added up, moved about, and reconfigured to make different qualifications, through common core competencies (and now employability skills). That is, the total equals the sum of the parts. This is the method that aggregates, and is less concerned with understanding the relationship between elements, and how these elements are transformed in the context of such a relationship.

The argument here says nothing about the way in which students should be taught the disciplines. Obviously teaching physics or mathematics to electricians should be different to teaching students undertaking degrees in these disciplines. This applies to all the regions of knowledge (which is where Bernstein locates the professions) that stand at the interface of a field of practice on the one hand, and disciplinary knowledge on the other, because the recontextualising principle used to select knowledge from the field in which it was produced and relocated in curriculum is the demands of practice (Bernstein 2000: 54). However, just like those students studying elite professions in elite universities, students in VET should have access to the disciplinary boundaries and the capacity to negotiate these boundaries in their practice. CBT renders these boundaries invisible.

\section{Conclusion}

The social composition of the VET and higher education sectors is different in Australia. Students from low socio-economic backgrounds are under-represented in higher education, while the VET sector is more representative of the broader community (Wheelahan and Moodie 2005). The implications from the above analysis are that CBT in VET reinforces class divisions through differentially distributing access to 'unthinkable' knowledge, because it does not allow students access to a 'style of reasoning' represented in disciplinary knowledge (Muller 2000), and consequently, focuses on specific content rather than the generative principles that underpin disciplinary knowledge. Bernstein's analysis of the structures of knowledge and the way in which access to it is differentially distributed provides insights into the social reasons why access to disciplinary knowledge is important, while critical realism provides insights into the epistemic reasons. A social justice strategy in Australia must not be premised solely on increasing access to higher education for working class students, although this is important. It must also be premised on overturning competency-based training as the mandated model of curriculum for all VET qualifications, and emphasising once again the importance of disciplinary knowledge as a component of VET qualifications. Electricians need to think like mathematicians, and community development workers like sociologists. We need to value the depth and complexity of knowledge needed for vocational practice in the same we do for professional practice.

\section{Acknowledgements}

I'd like to thank the two anonymous reviewers for their extremely helpful and productive suggestions on an earlier draft of this paper. I'd also like to thank Professor Johan Muller from the University of Capetown for his very generous and helpful suggestions on an earlier draft.

\section{Endnotes}


${ }^{1}$ See Moore (2004: chapter 6) for a critique of relativist theories of knowledge

2 Bernstein (2000: 113) distinguishes between the production of knowledge and the reproduction of knowledge. He says that all knowledge is delocated from the site in which it was produced (for example, in research in physics departments) and relocated into pedagogic discourse (for example, as part of the physics curriculum in school), because the whole field of knowledge production cannot be reproduced in entirety in the curriculum. This means that a process of selection and recontextualisation must take place. However, while the field of physics production is not the same as the field of physics reproduction in the curriculum, they are related by the way in which knowledge is classified within the discipline. My point here is different, because CBT severs the relationship between the field of knowledge production and its associated field of knowledge reproduction in curriculum.

\section{References:}

Archer, Margaret (1995) Realist social theory: the morphogenetic approach, Cambridge: Cambridge University Press.

Bates, Inge; Bloomer, Martin; Hodkinson, Phil; and Yeomans, David (1998) "Progressivism and the GNVQ: context, ideology and practice," Journal of Education and Work 112: 109-126.

Beck, John and Young, Michael (2005) "The assault on the professions and the restructuring of academic and professional identities: a Bernsteinian analysis," British Journal of Sociology of Education 26(2): 183197.

Bernstein, Basil (2000) Pedagogy, Symbolic Control and Identity, $2^{\text {nd }}$ ed., Oxford: Rowman \& Littlefield Publishers.

Bhaskar, Roy (1998) The Possibility of Naturalism: A Philosophical Critique of the Contemporary Human Sciences, $3^{\text {rd }}$ ed., London: Routledge.

Bloomer, Martin (1998) "'They Tell You What to Do and Then They Let You Get On with It': the illusion of progressivism in GNVQ," Journal of Education and Work 11(2): 167-186.

Cleary, Mitch; Flynn, Rosalie; and Thomasson, Seth (2006) Employability Skills. From Framework to Practice. An Introductory Guide for Trainers and Assessors, Canberra: Department of Education, Science and Training.

Collier, Andrew (1997) "Unhewn demonstrations," Radical Philosophy 81: 22-26.

Collier, Andrew (1998) "Stratified explanation and Marx's conception of history", in Archer, Margaret; Bhaskar, Roy; Collier, Andrew; Lawson, Tony; and Norrie, Alan (Eds.), Critical Realism: Essential Readings, London: Routledge.

Community Services and Health Industry Skills Council (2005) CHC02 Community Services Training Package Volume 3 of 4 National Competency Standards, Melbourne: Australian Training Products Ltd.

Department of Education Science and Training (2005) Training Package Development Handbook, October Canberra: DEST.

Durkheim, Emile (1967) The Elementary Forms of Religious Life, New York: The Free Press.

Goozee, Gillian (2001) The development of TAFE in Australia, $3^{\text {rd }}$ ed., Adelaide: National Centre for Vocational Education Research.

Jones, Lynn and Moore, Rob (1995) "Appropriating Competence: the competency movement, the New Right and the 'culture change' project," British Journal of Education \& Work 8(2): 78-92.

Moore, Rob (2004) Education and Society: Issues and Explanations in the Sociology of Education, Cambridge: Polity Press. 
Moore, Rob and Maton, Karl (2001) "Founding the Sociology of Knowledge: Basil Bernstein, Intellectual Fields and the Epistemic Device", in Morais, Ana; Neves, Isabel; Davies, Brian; and Daniels, Harry (Eds.), Towards a Sociology of Pedagogy. The Contribution of Basil Bernstein to Research, New York: Peter Lang.

Moore, Rob and Muller, Johan (2002) "The Growth of Knowledge and the Discursive Gap," British Journal of Sociology of Education 23(4): 627-637.

Muller, Johan (2000) Reclaiming Knowledge. Social Theory, Curriculum and Education Policy, London: RoutledgeFalmer.

Priestley, Mark (2002) "Global discourses and national reconstruction: the impact of globalization on curriculum policy," The Curriculum Journal 13(1): 121-138.

Sayer, Andrew (2000) Realism and Social Science, London: Sage.

Schofield, Kay and McDonald, Rod (2004) Moving on... Report of the High Level Review of Training Packages, April Brisbane: Australian National Training Authority.

Smith, Erica and Keating, Jack (2003) From Training Reform to Training Packages, Tuggerah: Social Science Press.

Wheelahan, Leesa and Moodie, Gavin (2005) "Separate post-compulsory education sectors within a liberal market economy: interesting models generated by the Australian anomaly", in Gallacher, Jim and Osborne, Mike (Eds.), A contested landscape: International perspectives on diversity in mass higher education, Leicester: NIACE.

Williams, Carolyn (2005) "The discursive construction of the 'competent' learner-worker: from Key Competencies to 'employability skills'," Studies in Continuing Education 27(1): 33-49.

Young, Michael (2003) "Durkheim, Vygotsky and the Curriculum of the Future," London Review of Education 1(2): 100-117. 